\title{
Multivariate method to identify inequalities in oral healthcare access
}

\author{
Emílio Prado Da Fonseca ${ }^{1}$
}

Correspondence: Dr. Emílio Prado Da Fonseca

Email: emiliopraddo@ig.com.br
'Department of Health Surveillance, Divinópolis, Minas Gerais, Brazil

\section{ABSTRACT}

Objective: The aim of this study is to apply a multivariate method for municipality's classification according access to oral health in adults. Materials and Methods: This is a cross-sectional epidemiological study. Were used multivariate classification called nonhierarchical cluster analysis K-means. The strategy brings together municipalities' similarity as access to oral health, where the most similar are next and the most different from getting further away. In addition, it allows reducing the intragroup variance and maximizing intergroup variance. It was assumed the number of four groups. Results: Among adults, 3,185 (52.63\%) visited the dentist less than a year, and $357(5.90 \%)$ have never been to the dentist. Homogeneous groups showed differences in the time since the last visit to the dentist for adults. The analysis of variance by the F statistic rejected the hypothesis that the variances are equal for the variables related to the time since the last visit to the dentist. Conclusion: It was possible to identify the inequalities in the access to oral healthcare services for adults and locate spatially municipalities whose subjects take longer to visit the dentist.

Key words: Access to health services, multivariate analysis, oral health and unified health system

\section{INTRODUCTION}

Dental healthcare services differ greatly among countries regarding organization, accessibility, availability, and cost. ${ }^{[1-20]}$ In some countries, full dental health services are readily available through private or public systems..$^{[1,2,4]}$ Countries that offer universal coverage of health services providing a healthcare package to all citizens, without suffering financial hardship when paying for them. ${ }^{[4]}$

The aim of this study was to apply a multivariate method to classify the access to oral health in adults.

\begin{tabular}{|l|l|}
\hline \multicolumn{2}{|c|}{ Access this article online } \\
\hline Quick Response Code: & \\
\hline
\end{tabular}

\section{MATERIALS AND METHODS}

Data were extracted from the epidemiological survey of the Oral Health Conditions of the Population of the State of São Paulo (SBSP-2015) with 161 municipalities in 2015. ${ }^{[21]}$ The data are available at Figshare public data repository - Licence CC BY 4.0 (DOI: 10.6084/ m9.figshare. 5286025.v1). Subjects were chosen by conglomerate/cluster sampling with probabilities proportional to the population size, taking into consideration the sample weight and effect of design on the respective stages of the draw. ${ }^{[21]}$ The sample size was calculated using the mean values of dental caries; prevalence of periodontal conditions;

This is an open access journal, and articles are distributed under the terms of the Creative Commons Attribution-NonCommercial-ShareAlike 4.0 License, which allows others to remix, tweak, and build upon the work non-commercially, as long as appropriate credit is given and the new creations are licensed under the identical terms.

For reprints contact: reprints@medknow.com

How to cite this article: Da Fonseca EP. Multivariate method to identify inequalities in oral healthcare access. Eur J Dent 2018;12:475-9.

DOI: 10.4103/ejd.ejd_317_17 
prevalence of use and need for dental prosthesis; with the respective standard deviations; acceptable error margins $(\varepsilon)$; design effects ( $\operatorname{deff}=2$ ), and non-response rates of $30 \%$. Finally, a sample of 6051 adults aged 35-44 years from State of São Paulo, Brazil, was obtained. ${ }^{[21]}$ Training and calibration processes of the dental teams were conducted by the gold-standard examiner with level of interrater agreement statistic Kappa of over $\kappa>0.76 .{ }^{[21]}$

The municipalities were classified through the nonhierarchical K-means multivariate grouping technique. ${ }^{[18,19,22]} \mathrm{K}$-means is one of the simplest unsupervised learning algorithms that solve the well-known clustering problem. ${ }^{[22]}$ The procedure follows a simple and easy way to classify a given data set through a certain number of clusters (assume k clusters) fixed a priori. The main idea is to define $\mathrm{k}$ centroids, one for each cluster. These centroids should be placed in a cunning way because of different location causes different result. The next step is to take each point belonging to a given data set and associate it to the nearest centroid. At this point, we need to recalculate $k$ new centroids as barycenters of the clusters resulting from the previous step. After we have these $\mathrm{k}$ new centroids, a new binding has to be done between the same data set points and the nearest new centroid. Finally, this algorithm aims at minimizing an objective function, in this case, a squared error function. The number of 4 groups (A, B, C, and D) was admitted, and the name of the municipality was defined as variable identifying the cluster. ${ }^{[18,19]}$ The variable "last dental visit" was used as input variable for the formation of homogeneous groups. Previous studies have used thematic maps to visualize the results of multivariate classification and visualization of homogeneous groups (clusters). ${ }^{[18,19,23]}$

The F statistic was used to test the hypothesis that the sample variances are equal (H0) and with a level of statistical significance $(\alpha=0.05) \cdot{ }^{[19]}$ The correlation compared the variability among the means of the formed groups. ${ }^{[19]}$

Research Ethics Committee of Dentistry College of Piracicaba approved the study with number 111/2015.

\section{RESULTS}

There was a decreasing order in the number of municipalities belonging to each group, and Group " $\mathrm{A}$ " showed 62 municipalities and Group " $\mathrm{D}$ " 10 municipalities [Figure 1].

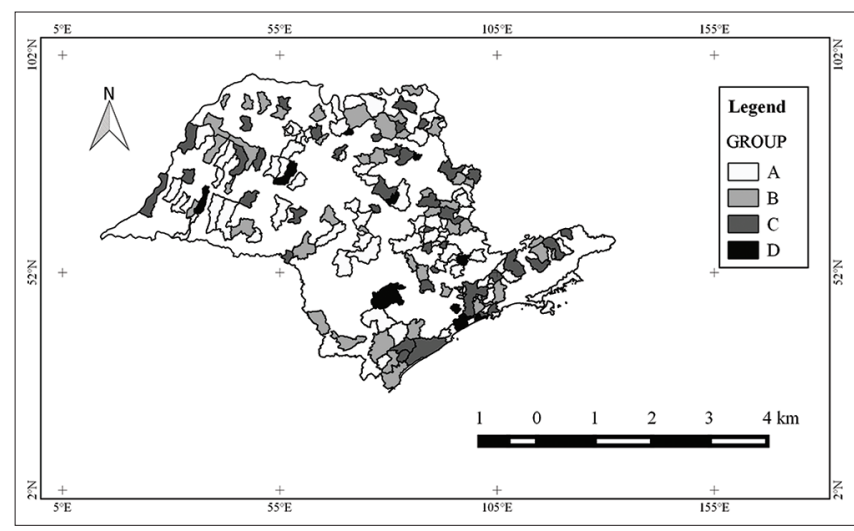

Figure 1: Distribution of municipalities according to the time since the last visit to the dentist, São Paulo, 2016

Among adults, 3185 (52.63\%) have been to the dentist less than a year, and $357(5.90 \%)$ have never been to the dentist. Group A represented municipalities whose individuals took an average of more time or never visited the dentist. Groups B and C represent the municipalities where adults visited the dentist less time. The hypothesis of equal variances for researched variables was rejected and the individuals who took the most time to visit the dentist [Table 1].

Boxplot summarized robust measures of central tendency and dispersion, with Group A presenting the worst median and Group B the largest. Among the municipalities that visited the dentist more than 3 years, there was an inequality in the distribution of the outcome, mainly for Groups A and C [Figure 2].

The paid service was the most used by adults, motivated by demands for treatment and well evaluated by the user, and 1046 (18.75\%) were motivated by toothache and $617(11.04 \%)$ for tooth extraction [Table 2].

The use of the public oral healthcare service was inversely proportional to fee for service/ private health insurance and directly motivated by pain, extraction, treatment, and evaluated positively. Adults who fee for service or private health insurance were directly related to the reason for negative review and evaluation of the service. Dental extraction was directly related to the use of the publicoral health care service [Table 3].

\section{DISCUSSION}

The multivariate classification process employed was able to identify significant and important differences in access to oral health services.

It was observed that the demands for public dental services were high; however, it was the private sector 
Fonseca: Method to identify inequalities in oral health care

\begin{tabular}{|c|c|c|c|c|c|c|}
\hline \multirow[t]{2}{*}{ Dental visit } & \multicolumn{4}{|c|}{$n$ (mean of groups) } & \multirow[t]{2}{*}{$n$ (mean) } & \multirow[t]{2}{*}{$F^{*}$} \\
\hline & A & B & C & D & & \\
\hline$<1$ year ago & $888(0.39)$ & $1.033(0.69)$ & $1.049(0.56)$ & $215(0.49)$ & $3.185(0.53)$ & $\overline{44.44}$ \\
\hline 1 or 2 years ago & $626(0.28)$ & $289(0.19)$ & $469(0.25)$ & $89(0.19)$ & $1.473(0.24)$ & 99.97 \\
\hline 3 or more years ago & $499(0.23)$ & $150(0.10)$ & $293(0.16)$ & $94(0.22)$ & $1.036(0.17)$ & 92.90 \\
\hline Never had a dental visit & 244 & 27 & 46 & 40 & 357 & - \\
\hline
\end{tabular}

Table 2: Profile of the groups of municipalities according to means of the variables of access to the oral health service by adults, São Paulo, 2016

\begin{tabular}{|c|c|c|c|c|c|c|c|c|c|c|c|}
\hline \multirow[t]{3}{*}{ Negative } & \multicolumn{8}{|c|}{ Groups } & \multirow{2}{*}{\multicolumn{2}{|c|}{ Mean }} & \multirow[t]{3}{*}{$F^{*}$} \\
\hline & \multicolumn{2}{|c|}{ A } & \multicolumn{2}{|c|}{ B } & \multicolumn{2}{|c|}{ C } & \multicolumn{2}{|c|}{ D } & & & \\
\hline & $n$ & Mean & $n$ & Mean & $n$ & Mean & $n$ & Mean & $n$ & Mean & \\
\hline \multicolumn{12}{|l|}{ Payment model } \\
\hline Public insurance & 884 & 0.39 & 614 & 0.42 & 649 & 0.37 & 141 & 0.34 & 2.288 & 0.39 & 26.43 \\
\hline Fee for service & 1.251 & 0.56 & 765 & 0.53 & 1.119 & 0.59 & 286 & 0.64 & 3.421 & 0.56 & 23.60 \\
\hline \multicolumn{12}{|l|}{ Demand } \\
\hline Regular visit & 534 & 0.23 & 335 & 0.22 & 437 & 0.24 & 87 & 0.18 & 1.393 & 0.23 & 49.29 \\
\hline Toothache & 402 & 0.17 & 258 & 0.18 & 306 & 0.17 & 80 & 0.17 & 1.046 & 0.17 & 78.95 \\
\hline $\begin{array}{l}\text { Dental } \\
\text { extraction }\end{array}$ & 235 & 0.11 & 144 & 0.10 & 191 & 0.09 & 47 & 0.10 & 617 & 0.10 & 137.88 \\
\hline Treatment & 910 & 0.40 & 630 & 0.42 & 786 & 0.41 & 204 & 0.49 & 2.530 & 0.42 & 32.53 \\
\hline \multicolumn{12}{|l|}{ Visit evaluation } \\
\hline Positive & 2.067 & 0.91 & 1.318 & 0.89 & 1.669 & 0.91 & 408 & 0.93 & 5.462 & 0.90 & 33.12 \\
\hline Negative & 55 & 0.02 & 47 & 0.03 & 64 & 0.03 & 15 & 0.04 & 181 & 0.03 & 865.83 \\
\hline
\end{tabular}

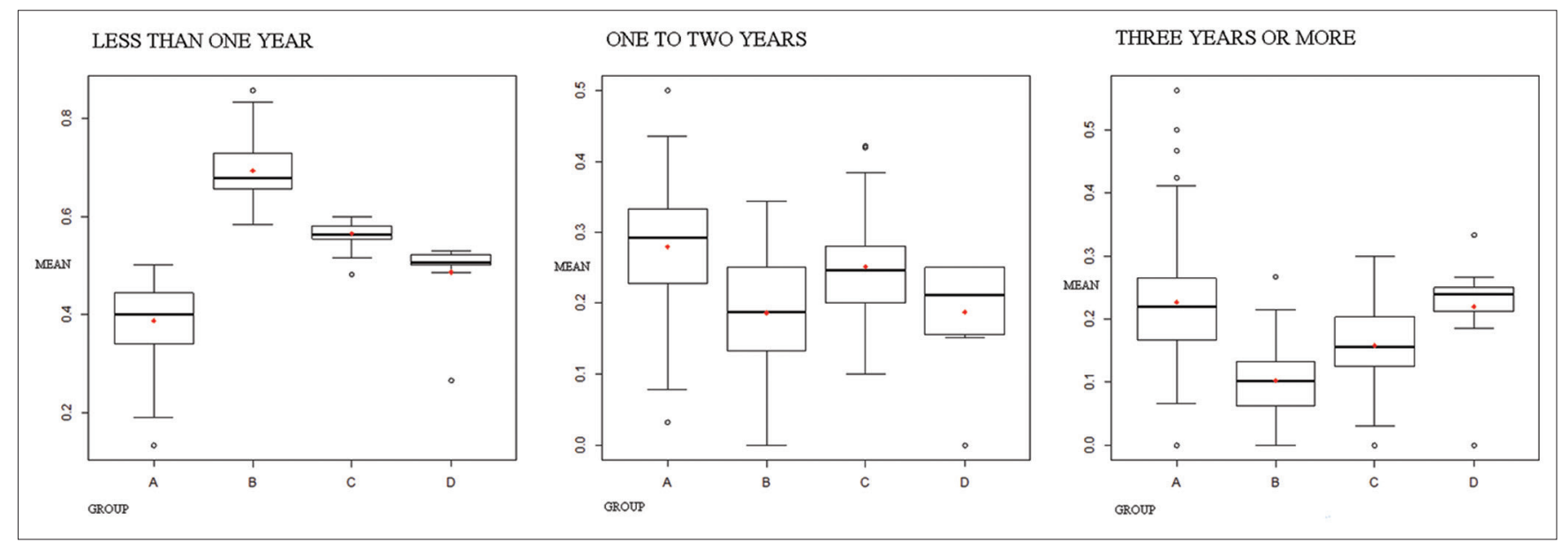

Figure 2: Boxplot of the groups according to the average time since the last visit to the dentist, São Paulo, 2016

that responded by the greater coverage of these services. The improvement in the average income of the Brazilian population may influence the higher demand for the paid dental service. ${ }^{[2-4,9,24]}$ In this study, a higher prevalence of consultations was found in private practices and corroborates previous studies; however, ${ }^{\text {the }}$ prevalence values were divergent and can be explained by the methodological differences between the studies. Another important result is the correlation of the negative evaluation of the private services or by plan and can be explained by the fact that individuals with better socioeconomic conditions tend to have better schooling and evaluate more critically the service received. ${ }^{[9]}$

The results also provide information on the geographical behavior of the main untreated oral conditions in Brazil. ${ }^{[20,24]}$ Adults who never attended a dentist had toothache or went to the dentist to extract a tooth indicate a serious epidemiological picture of 
Fonseca: Method to identify inequalities in oral health care

\begin{tabular}{|c|c|c|c|c|c|c|c|c|}
\hline Variable & Public insurance & Fee for service & Regular visit & Toothache & Dental extraction & Treatment & Positive & Negative \\
\hline Public insurance & 1.00 & $-0.68^{*}$ & -0.06 & $0.15^{\star *}$ & $0.26^{*}$ & $0.11^{*}$ & $0.33^{*}$ & -0.07 \\
\hline Fee for service & -0.68 & 1.00 & $0.27^{\star *}$ & 0.04 & -0.12 & $0.20^{* *}$ & $0.35^{*}$ & $0.17^{* *}$ \\
\hline Regular visit & -0.06 & $0.27^{\star *}$ & 1.00 & -0.09 & $0.19^{* *}$ & $-0.37^{*}$ & $0.27^{* *}$ & -0.01 \\
\hline Toothache & $0.15^{\star *}$ & 0.04 & -0.09 & 1.00 & -0.08 & $-0.25^{\star \star}$ & $0.28^{* *}$ & 0.04 \\
\hline Dental extraction & $0.26^{*}$ & -0.12 & $-0.19^{* *}$ & -0.08 & 1.00 & -0.06 & $0.18^{* *}$ & 0.14 \\
\hline Treatment & $0.11^{*}$ & $0.20^{* *}$ & $-0.37^{*}$ & $-0.25^{\star \star}$ & -0.06 & 1.00 & $0.43^{*}$ & 0.12 \\
\hline Positive & $0.33^{*}$ & $0.35^{\star}$ & $0.27^{\star *}$ & $0.28^{* *}$ & $0.18^{* *}$ & $0.43^{*}$ & 1.00 & 0.02 \\
\hline Negative & -0.07 & $0.17^{* *}$ & -0.01 & 0.04 & 0.14 & 0.12 & 0.02 & 1.00 \\
\hline
\end{tabular}

the Brazilian adult population. ${ }^{[3,7]}$ The cohort effect resulting from the past exposures to certain risk factors may reflect on the oral condition of the adults interviewed. ${ }^{[25]}$

The positive evaluation obtained a high prevalence and was similar to that found in a previous study. ${ }^{[7]}$ On the other hand, the low prevalence of individuals who evaluated negatively the received service found in this study is based on the acceptance in the cultural question of acceptance of the oral health condition as a natural phenomenon of the aging process.

This study has a cross-sectional design, and causality has not been studied. The "time since the last visit to the dentist" is a variable that depends on the respondent's memory, and memory bias may have occurred.

\section{CONCLUSION}

The classification method identified the spatial pattern of distribution and inequality of access to oral health in adults. In addition, was possible visualize, when, where and why the adult individuals living in São Paulo State are seeking to improve the oral health condition and provide subsidies for planning in oral health according to demands of the population.

\section{Acknowledgment}

The authors would like to thank the Coordenação de Aperfeiçoamento de Pessoal de Nível Superior (CAPES) for the grant received to support this study.

\section{Financial support and sponsorship}

This study was financially supported by Coordenação de Aperfeiçoamento de Pessoal de Nível Superior (CAPES).

\section{Conflicts of interest}

There are no conflicts of interest.

\section{REFERENCES}

1. Beaglehole R, Benzian H, Crail J, Mackay J. The Oral Health Atlas: Mapping a Neglected Global Health First Edition. FDI World Dental Education and Myriad Editions; 2009.

2. O'Donnell O. Access to health care in developing countries: Breaking down demand side barriers. Cad Saude Publica 2007;23:2820-34.

3. Manhães AL, Costa AJ. Access to and utilization of dental services in the state of Rio De Janeiro, Brazil: An exploratory study based on the 1998 national household sample survey. Cad Saude Publica 2008;24:207-18.

4. Pucca GA Jr., Gabriel M, de Araujo ME, de Almeida FC. Ten years of a national oral health policy in Brazil: Innovation, boldness, and numerous challenges. J Dent Res 2015;94:1333-7.

5. Soares CL, Paim JS. Critical issues for implementing oral health policy in the city of Salvador, Bahia State, Brazil. Cad Saude Publica 2011;27:966-74.

6. Antunes JL, Narvai PC. Dental health policies in Brazil and their impact on health inequalities. Rev Saude Publica 2010;44:360-5.

7. Health Ministry. Department of Health Care. National Coordination of Oral Health. SB Brazil 2010: National Oral Health Survey; 2012.

8. Camargo MB, Dumith SC, Barros AJ. Regular use of dental care services by adults: Patterns of utilization and types of services. Cad Saude Publica 2009;25:1894-906.

9. Peres KG, Peres MA, Boing AF, Bertoldi AD, Bastos JL, Barros AJ, et al. Reduction of social inequalities in utilization of dental care in Brazil from 1998 to 2008. Rev Saude Publica 2012;46:250-8.

10. Pinheiro RS, Torres TZ. Access to oral health services between Brazilian States. Cien Saude Colet 2006;11:999-1010.

11. Gomes AM, Thomaz EB, Alves MT, Silva AA, Silva RA. Factors associated with use of oral health services: A population-based study in municipalities of the state of Maranhão, Brazil. Cien Saude Colet 2014;19:629-40.

12. Baldani MH, Antunes JL. Inequalities in access and utilization of dental services: A cross-sectional study in an area covered by the family health strategy. Cad Saude Publica 2011;27 Suppl 2:S272-83.

13. Pereira CR, Patrício AA, Araújo FA, Lucena EE, Lima KC, Roncalli AG, et al. Inclusion of oral health teams in the family health program and its impact on the use of dental services. Cad Saude Publica 2009;25:985-96

14. Araújo CS, Lima Rda C, Peres MA, Barros AJ. Use of dental services and associated factors: A population-based study in Southern Brazil. Cad Saude Publica 2009;25:1063-72.

15. Assis MM, de Jesus WL. Access to health services: Approaches, concepts, policies and analysis model. Cien Saude Colet 2012;17:2865-75.

16. Aday LA, Andersen R. A framework for the study of access to medical care. Health Serv Res 1974;9:208-20.

17. Travassos C, Martins M. A review of concepts in health services access and utilization. Cad Saude Publica 2004;20 Suppl 2:S190-8.

18. Carvalho MS, Cruz OG, Nobre FF. Risk profile: Multivariate cluster analysis of urban small areas based on socioeconomic indicators - Census tracts from the greater Rio De Janeiro metropolitan area. Cad Saude Publica 1997;13:635-45.

19. Santos SM, Noronha CP. Mortality spatial patterns and socioeconomic differences in the city of Rio De Janeiro. Cad Saude Publica 2001;17:1099-110.

20. Moreira Rda S, Nico LS, Tomita NE. The relation between space and 
collective oral health: For a georeferenced epidemiology. Cien Saude Colet 2007;12:275-84.

21. Pereira AC, Frias AC, Vieira V. Oral Health Survey of São Paulo State - SBSP 2015 - Final Report. Livronovo publisher; 2016. Available from: http://www.w2.fop.unicamp.br/sbsp2015/. [Last accessed on 2017 Jul 15].

22. Gelbard R, Goldman O, Spiegler I. Investigating diversity of clustering methods: An empirical comparison. Data Knowl Eng 2007;63:155-66.
23. Bailey TC. Spatial statistical methods in health. Cad Saude Publica 2001;17:1083-98.

24. Moreira Rda S, Nico LS, Tomita NE, Ruiz T. Oral health of Brazilian elderly: A systematic review of epidemiologic status and dental care access. Cad Saude Publica 2005;21:1665-75.

25. Lima-Costa MF, Barreto SM, Giatti L. Health status, physical functioning, health services utilization, and expenditures on medicines among Brazilian elderly: A descriptive study using data from the National Household Survey. Cad Saude Publica 2003;19:735-43. 